\title{
Corrosion-wear behavior of a biocompatible magnesium matrix composite in simulated body fluid
}

\author{
Jinlong SU ${ }^{1}$, Jie TENG ${ }^{1, *}$, Zili XU' ${ }^{2, *}$, Yuan $\mathbf{L I}^{2}$ \\ ${ }^{1}$ College of Materials Science and Engineering, Hunan University, Changsha 410082, China \\ ${ }^{2}$ The First Affiliated Hospital, Hunan Normal University, Changsha 410006, China \\ Received:28 July 2019 / Revised: 22 October 2019 / Accepted: 03 January 2020 \\ (C) The author(s) 2020 .
}

\begin{abstract}
Magnesium matrix composites are a new generation of biocompatible implant materials, but they will inevitably undergo simultaneous wear and corrosion in the human body. In this study, hydroxyapatite $\left(\mathrm{Ca}_{10}\left(\mathrm{PO}_{4}\right)_{6}(\mathrm{OH})_{2}, \mathrm{HA}\right)$ is used in a magnesium matrix composite to study its effects on the corrosion-wear behavior. Two samples (a magnesium alloy composed of $\mathrm{Mg}$, Zn, and $\mathrm{Zr}$ (ZK60) alloy and ZK60/10HA composite) were fabricated using the powder metallurgy (PM) process. Their corrosion-wear behavior was investigated using the sliding wear test in a simulated body fluid (SBF). At all the sliding velocities tested, the corrosionwear resistance of ZK60/10HA was superior to ZK60. At a sliding velocity of $942.5 \mathrm{~mm} / \mathrm{min}$, ZK60/10HA demonstrated a $42 \%$ improvement in corrosion-wear resistance compared to ZK60. For ZK60, the main wear mechanism under dry conditions was abrasion, while the wear mechanisms in the SBF were abrasion and corrosion. For ZK60/10HA, the wear mechanisms under dry conditions were abrasion and delamination, while in SBF they were mainly abrasion and corrosion, accompanied by slight delamination. The results indicated that HA particles can be used as an effective corrosion-wear inhibitor in biocompatible magnesium matrix composites.
\end{abstract}

Keywords: corrosion-wear; magnesium matrix composite; hydroxyapatite (HA); biomaterial

\section{Introduction}

Metallic materials (such as titanium (Ti) and its alloys, cobalt-chromium (Co-Cr) alloys, and stainless steel) are preferred over ceramics and polymer materials for orthopedic applications due to their unique comprehensive performance $[1,2]$. These traditional implant materials are bio-inert in vivo, and need to be retracted through secondary surgery after the tissues have recovered. The retraction process, which can cause physical pain and patient morbidity, could be avoidable if the implants were biodegradable in vivo. Another disadvantage of these materials is that they possess a much higher elastic modulus than natural bones, which can result in a stress shielding effect that is detrimental to new bone growth [3].
Magnesium (Mg) has attracted great attention as a new generation of implant material due to its excellent biocompatibility and relatively low elastic modulus [4]. The elastic modulus of Mg (approximately $45 \mathrm{GPa}$ ) is much lower than traditional metallic orthopedic implants such as stainless steel (189-205 GPa), cobaltchromium alloys (230 GPa), and titanium alloys (105$117 \mathrm{GPa})$. The elastic modulus of natural bone is approximately 3-20 GPa. Hence, Mg and its alloys can effectively alleviate the effect of stress shielding.

The main factor that restricts the biomedical application of $\mathrm{Mg}$ alloys is its excessive degradation rate and poor wear resistance, which would invalidate the orthopedic implant before the bone tissue has completely recovered [4]. Hydroxyapatite $\left(\mathrm{Ca}_{10}\left(\mathrm{PO}_{4}\right)_{6}(\mathrm{OH})_{2}\right.$ $\mathrm{HA}$ ), a type of bioactive ceramic, exhibits excellent

* Corresponding authors: Jie TENG, E-mail: tengjie@hnu.edu.cn; Zili XU, E-mail: xuzili4848@163.com 
biocompatibility, osteoconductivity, and bioactivity. Moreover, HA can induce the formation of a bone-like apatite layer in physiological environments [5, 6], which has the ability to mitigate the effects of corrosion. Due to these characteristics, HA is considered as an ideal reinforcement phase in biocompatible magnesium matrix composites. Previous studies have indicated that the addition of HA can effectively improve the corrosion resistance and biocompatibility of $\mathrm{Mg}$ alloys [7, 8]. Sunil et al. [9] fabricated $\mathrm{Mg} / x \mathrm{HA}(x=0,5,10$ and $15 \mathrm{wt} \%$ ) composites through ball milling and a spark plasma sintering method, and studied the corrosion behavior of these composites. The $\mathrm{Mg} / 10 \mathrm{HA}$ composite exhibited the best corrosion resistance, with lower inter-lamellar corrosion and higher resistance to localized pitting. In another study, del Campo et al. [10] synthesized $\mathrm{Mg} / x \mathrm{HA}(x=0,5,10$, and $15 \mathrm{wt} \%)$ composites using a powder metallurgy method that consists of mixing raw powders and consolidation by extrusion. They found that the $\mathrm{Mg} / 5 \mathrm{HA}$ composite exhibited the best corrosion resistance among these materials, while pure $\mathrm{Mg}$ exhibited a corrosion penetration rate that was five times greater than that of the $\mathrm{Mg} / 5 \mathrm{HA}$ composite after immersion in a phosphate buffered saline (PBS) solution for $100 \mathrm{~h}$. In addition, Jaiswal et al. [8] prepared Mg-3Zn matrix composites with $0,2,5$, and $10 \mathrm{wt} \%$ HA using powder pressing and a conventional sintering route, and the results showed that $\mathrm{Mg}-3 \mathrm{Zn} / 5 \mathrm{HA}$ exhibited the best corrosion resistance and biocompatibility among all the tested $\mathrm{Mg}-3 \mathrm{Zn} / \mathrm{HA}$ composites.

Currently, $\mathrm{Mg}$ is mainly used for the fixation of fractures (such as in bone plates and bone screws), which suffer from wear during the initial implantation process. Moreover, the interface between an implant and its surrounding tissue is a friction pair; hence, tribocorrosion has been observed at the contacting interfaces when subjected to minute relative movements $[11,12]$. This poor corrosion-wear resistance can lead to loosened implants or failure during service. In addition, long term fretting corrosion and tribocorrosion will lead to a significant increase in the degradation rate of the implant. The wear has a synergistic effect with the corrosion process, which leads to an accelerated degradation rate $[13,14]$. Based on these findings, it is clear that more studies into methods for improving the corrosion-wear resistance of biocompatible magnesium matrix composites is needed.

A magnesium alloy composed of $\mathrm{Mg}, \mathrm{Zn}$, and $\mathrm{Zr}$ (ZK60) was used as the magnesium matrix in this study, as it is a promising material for orthopedic applications. $\mathrm{Zn}$ is an essential trace element in the human body, and $\mathrm{Mg}-\mathrm{Zn}$ binary alloys exhibit great biocompatibility $[15,16]$. Furthermore, due to the grain refinement effect of $\mathrm{Zr}$, more favorable comprehensive performance can be achieved through the addition of $\mathrm{Zr}$ into a $\mathrm{Mg}-\mathrm{Zn}$ alloy [17]. As previously mentioned, HA is a component of natural bone that has excellent biocompatibility, osteoconductivity, and bioactivity. Due to its sufficient supply and low cost, HA has been widely used to substitute bone in repairs. Additionally, HA has a similar chemical and crystallographic structure to human bones, which can help in forming a chemical bond with the surrounding tissue [18]. Particularly, in a physiological environment, HA can induce the formation of a bone-like apatite, rendering it the most commonly used reinforcement phase in biocompatible magnesium matrix composites [5, 6, 19]. Previous studies have shown that the addition of HA particles can effectively enhance the corrosion-wear resistance of Ti6Al4V and CoCrMo alloys [20, 21]. However, the effect of HA on the corrosion-wear behavior of magnesium matrix composites has not yet been studied.

The aim of this study was to investigate the effects of HA on the corrosion-wear behavior of ZK60/HA composites. ZK60 alloy and ZK60/10HA composite were fabricated using a power metallurgy method. The wear behavior of ZK60 and ZK60/10HA under dry and simulated body fluid (SBF) conditions was systematically investigated. Their wear mechanisms were discussed based on the wear rate $\omega$ analysis and the morphology of the worn surfaces.

\section{Experimental}

\subsection{Materials preparation}

The ZK60 alloy reinforced with $10 \mathrm{wt} \%$ HA was fabricated using powder metallurgy. The gas-atomized ZK60 magnesium alloy powders (Zn $5.1 \mathrm{wt} \%$, Zr $0.18 w^{\circ} \%, 30-50 \mu \mathrm{m}$, Tangshan Weihao Magnesium Powder Co., Ltd., Tangshan, China) and HA powders (2-10 $\mu \mathrm{m}$, Beijing DK Nanotechnology Co., Ltd., 
Beijing, China) were selected as the matrix alloy and reinforcement phase, respectively. The morphology and particle size of the HA powders prior to milling are displayed in Fig. 1. In the first step, the ZK60 magnesium alloy powders were mechanically milled for $1.5 \mathrm{~h}$ at $400 \mathrm{rpm}$ with a planetary ball mill to remove the surface oxide film. Then, the ZK60 and HA powders were mixed evenly through ball milling in an agate tank. The rotation speed was $200 \mathrm{rpm}$ and the ball milling was performed for $30 \mathrm{~min}: 15 \mathrm{~min}$ in forward rotation, and $15 \mathrm{~min}$ in reverse rotation. The mixed powders were then placed in a mold under a vacuum environment at $5 \mathrm{~Pa}$, and they were heated to $180^{\circ} \mathrm{C}$ and pre-compacted at a force of $100 \mathrm{MPa}$ to obtain a powder ingot billet. The billet was further subjected to hot compression at a force of $500 \mathrm{MPa}$ for $10 \mathrm{~min}$ at $300{ }^{\circ} \mathrm{C}$, and then extruded with an extrusion ratio of 20:1. A bar of $10 \mathrm{~mm}$ diameter was obtained after extrusion. The ZK60 alloy bar was also produced by the same process without the addition of HA.

\subsection{Hardness test}

The Vickers micro-hardness was measured using a micro-hardness instrument (HVS-1000, Shanghai
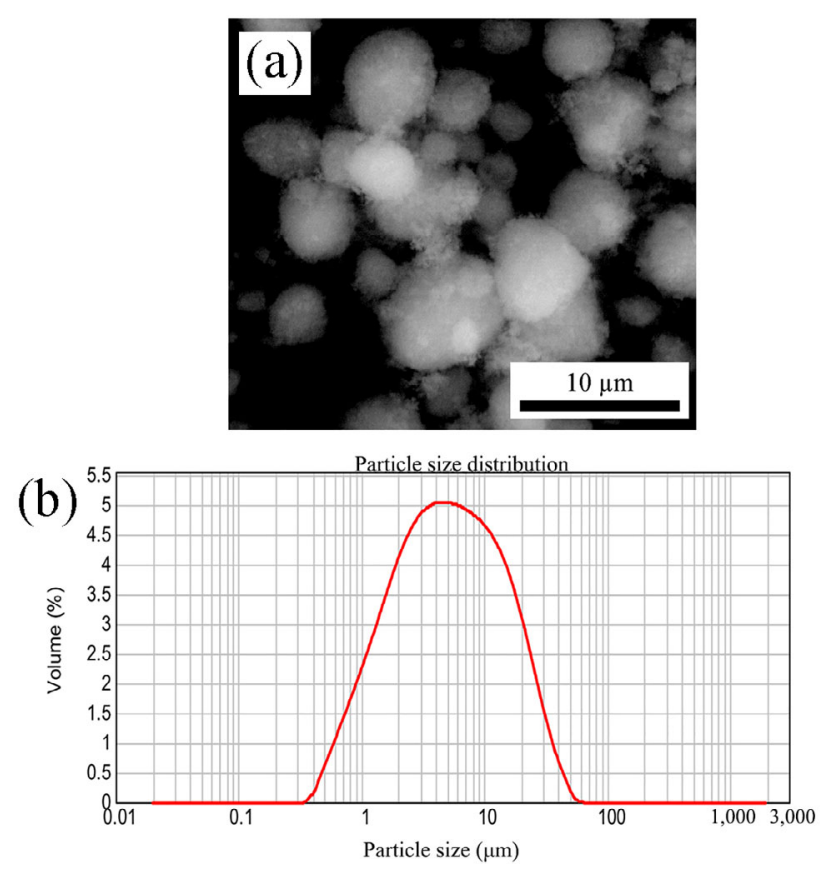

Fig. 1 (a) Transmission electron microscopy image and (b) particle size distribution of the HA powders prior to the milling process.
Caikang Optical Instruments Co., Ltd., Shanghai, China), with a load of $1 \mathrm{~N}$ that was held for $15 \mathrm{~s}$ along the transverse directions. Each sample was tested at least six times, and the mean value was taken as the hardness value.

\subsection{Electrochemical test}

The electrochemical tests were performed using an electrochemical workstation (CHI-660C, CH Instruments Inc., Shanghai, China). The ZK60 alloy and ZK60/10HA composites were used as the working electrode. A platinum electrode and a saturated calomel electrode were used as the auxiliary and reference electrodes, respectively. The working electrode was sealed in epoxy resin with an exposed geometric area of $0.78 \mathrm{~cm}^{2}$. The SBF solution was used as the electrolyte at a volume of $200 \mathrm{~mL}$. The ion concentration of the SBF solution is listed in Table 1. The SBF solution was prepared according to the study by Kokubo and Takadama [22]. Before measurements were taken, the open circuit potential (OCP) was tested until it stabilized. The scanning potential range was $\mathrm{OCP} \pm 200 \mathrm{mV}$, with a scanning rate of $1 \mathrm{mV} / \mathrm{s}$.

\subsection{Wear test}

The wear tests were conducted under dry and SBF conditions using a ball-on-disc tribometer (SFT-2M, Zhongke Kaihua Corporation, Lanzhou, China) with a GCr15 steel ball that had a hardness of $60 \mathrm{HRC}$, as shown in Fig. 2. The dry wear and corrosion-wear test samples, with a diameter of $10 \mathrm{~mm}$ and length of $4.5 \mathrm{~mm}$, were cut from the as-extruded bars using

Table 1 Ion concentrations of the SBF solution.

\begin{tabular}{ccc}
\hline \multirow{2}{*}{ Ion } & \multicolumn{2}{c}{ Ion concentration $(\mathrm{mM})$} \\
\cline { 2 - 3 } & Blood plasma & $\mathrm{SBF}$ \\
\hline $\mathrm{Na}^{+}$ & 142.0 & 142.0 \\
$\mathrm{~K}^{+}$ & 5.0 & 5.0 \\
$\mathrm{Mg}^{2+}$ & 1.5 & 1.5 \\
$\mathrm{Ca}^{2+}$ & 2.5 & 2.5 \\
$\mathrm{Cl}^{-}$ & 103.0 & 147.8 \\
$\mathrm{HCO}^{3-}$ & 27 & 4.2 \\
$\mathrm{HPO}^{4-}$ & 1.0 & 1.0 \\
$\mathrm{SO}_{4}^{2-}$ & 0.5 & 0.5 \\
$\mathrm{pH}^{3-}$ & $7.2-7.4$ & 7.40 \\
\hline
\end{tabular}




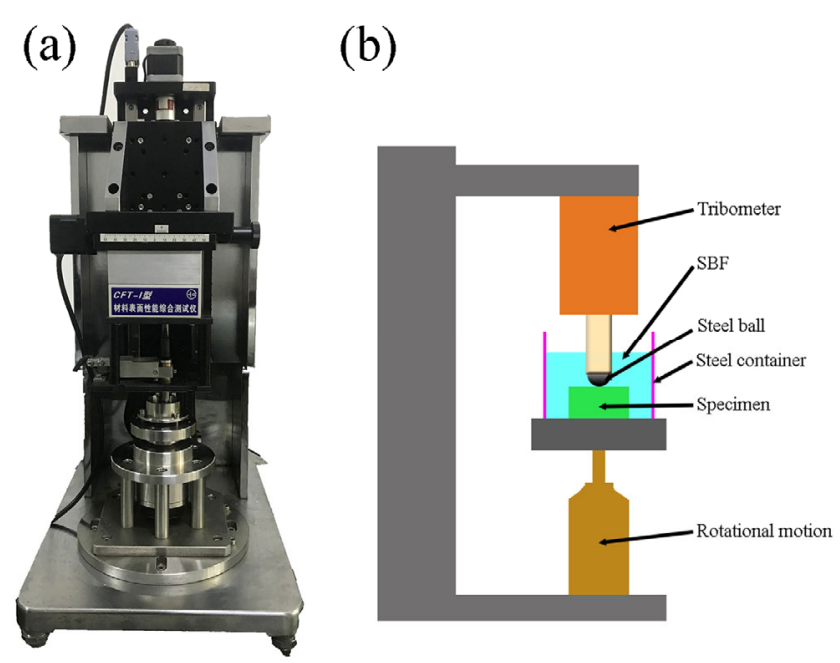

Fig. 2 (a) Digital photograph of the ball-on-disk tribometer and (b) a schematic diagram of the platform used for the sliding wear test in the SBF solution.

electrical discharge machining (EDM). Prior to the wear tests, all specimens were prepared by grinding up to 5,000-grit silicate paper, followed by ultrasonic cleaning in ethanol for $5 \mathrm{~min}$. The surface roughness of the samples prior to the tests was evaluated using a surface roughness tester (SJ-210, Mitutoyo, Japan).

The wear tests under the dry and SBF conditions were performed with a load of $5 \mathrm{~N}$ for $53 \mathrm{~min}$ and sliding velocities of $942.5,1,885,2,827.5,3,770$, and $4,712.5 \mathrm{~mm} / \mathrm{min}$. The radius of the wear tracks was $3 \mathrm{~mm}$, and the volume of the SBF solution used was $10 \mathrm{~mL}$. The worn volume was calculated from the cross-sectional area of the worn tracks, which was measured using a displacement sensor. The $\omega$ $\left(\mathrm{mm}^{3} /(\mathrm{N} \cdot \mathrm{m})\right)$ was calculated by the following equation:

$$
\omega=\frac{V}{F S}
$$

where $V$ is the worn volume $\left(\mathrm{mm}^{3}\right), F$ is the applied normal load $(\mathrm{N})$, and $S$ is the sliding distance $(\mathrm{m})$. The experiments were repeated at least three times under each experimental condition. After the sliding wear test, the sample was taken out and underwent ultrasonic cleaning in a chromic acid solution $(200 \mathrm{~g} / \mathrm{L}$ $\mathrm{CrO}_{3}+10 \mathrm{~g} / \mathrm{L} \mathrm{AgNO}_{3}$ ) for $5 \mathrm{~min}$ to remove corrosion products on the surface of specimens, followed by further washing with distilled water and ultrasonic cleaning in ethanol for $3 \mathrm{~min}$.

The maximum contact pressure $\left(P_{\max }\right)$ on the samples when loaded using a spherical indenter can be calculated by the following equation:

$$
P_{\max }=-0.578\left(\frac{F}{R^{2} W^{2}}\right)^{\frac{1}{3}}
$$

where $R$ is the radius of the ball, $W=\left(1-\gamma_{1}^{2}\right) / E_{1}+$ $\left(1-\gamma_{2}^{2}\right) / E_{2}$, and $E_{1}, E_{2}, \gamma_{1}$, and $\gamma_{2}$ represent the modulus of elasticity and Poisson's ratio of the samples and ball, respectively. Thus, conservative predictions of $P_{\max }(\mathrm{ZK} 60)=-562.1 \mathrm{MPa}$ and $P_{\max }(\mathrm{ZK} 60 / 10 \mathrm{HA})=$ $-594.8 \mathrm{MPa}$ were made. The value of $P_{\max }$ found here is comparable with a related study that found a $P_{\max }$ of $182 \mathrm{MPa}$ for a HA-10Ti composite [23]. The load of $5 \mathrm{~N}$ was chosen for effectively simulating the worn surface and $\omega$. During the sliding process, the contact area increases and the pressure decreases because of how the ball-on-disk measurement is performed. As a result, the actual pressure experienced by the samples in this study was much lower than the calculated $P_{\max }$.

\subsection{Characterization}

The microstructure of the samples was characterized using a metallographic microscope (4XCE, Shanghai Caikang Optical Instruments Co., Ltd., Shanghai, China) and X-ray diffraction (SmartLab, Rigaku Corporation, Japan) with $\mathrm{Cu} \mathrm{K} \alpha$ radiation $(\lambda=1.5418 \AA$ ). The relative densities of the samples were measured according to Archimedes' principle. Scanning electron microscopy (EVO MA10, Carl Zeiss, Germany) and energydispersive X-ray spectroscopy (EDS) were used to examine the worn surfaces of the samples and the debris produced.

\section{Results}

\subsection{Microstructure analysis}

Figures 3(a) and 3(b) show the optical microscopy (OM) images of ZK60 and ZK60/10HA, respectively. The HA particles were distributed along the grain boundary, and some of the HA particles were agglomerated. Based on liner measurements, the mean grain size in the ZK60 and ZK60/10HA samples were 51 and $44 \mu \mathrm{m}$, respectively. With the addition of $10 \mathrm{wt} \%$ HA, the grain size of ZK60/10HA was refined by $14 \%$ relative to ZK60. The grain refinement can be attributed 

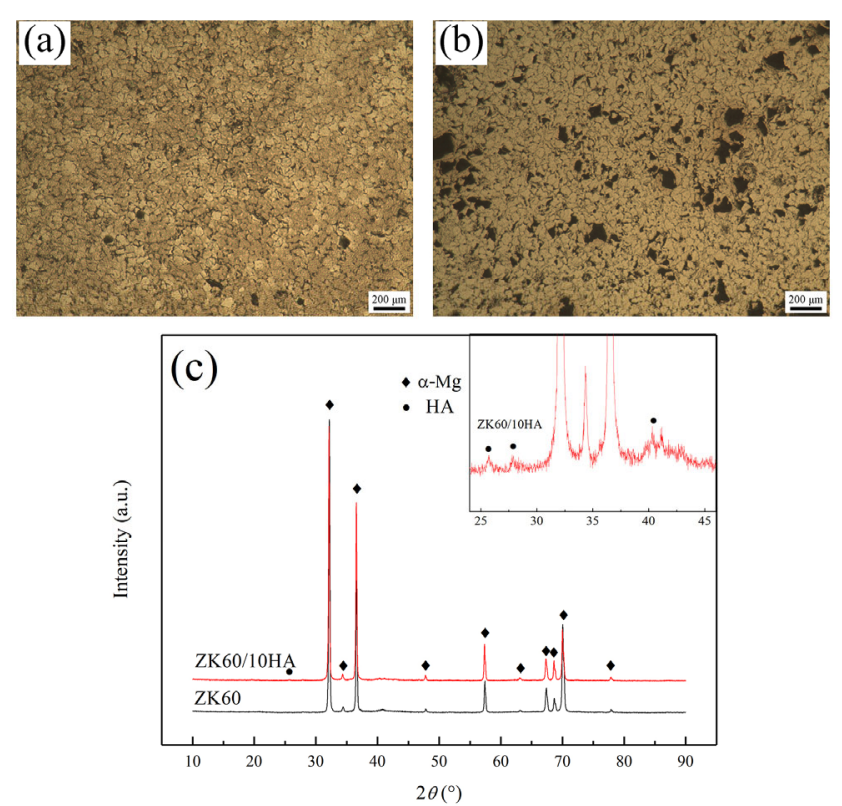

Fig. 3 OM images of the transverse cross-section of (a) ZK60 and (b) ZK60/10HA, and (c) XRD patterns of ZK60 and ZK60/10HA.

to the large stress concentration inside the grain during the extrusion process. Moreover, HA particles have the ability to inhibit the grain growth, which is another important factor causing grain refinement [6]. Figure 3(c) displays the XRD patterns of ZK60 and ZK60/10HA. The ZK60/10HA composite consisted of two phases $(\alpha-\mathrm{Mg}$ and HA), and there was no new phase formed during the manufacturing process. For both ZK60 and $\mathrm{ZK} 60 / 10 \mathrm{HA}$, the typical intermetallic $\mathrm{MgZn}_{2}$ phase was not detected, which could be due to the rapid cooling caused by the gas atomization of the magnesium matrix powders that occurred when $\mathrm{Zn}$ was dissolved into $\mathrm{Mg}$ to form a supersaturated solid solution. In the subsequent powder metallurgy processing, the $\mathrm{MgZn}_{2}$ phase did not precipitate; hence, it could not be detected.

The micro-hardness and relative density of ZK60 and ZK60/10HA are listed in Table 2. The microhardness of ZK60 and ZK60/10HA are 110.2 and 106.4 HV, respectively. The decrease in hardness of ZK60/10HA can be attributed to HA particle agglomeration, which caused increased porosity in the sample [24]. The relative density of the samples decreased from $99.7 \%$ to $97.3 \%$ with the incorporation of HA. This confirms that some voids were formed in the composite.
Table 2 Transverse cross-sectional micro-hardness, and the theoretical and experimental density values for ZK60 and ZK60/ $10 \mathrm{HA}$.

\begin{tabular}{ccccc}
\hline Sample & $\begin{array}{c}\text { Micro-hardness } \\
(\mathrm{HV})\end{array}$ & $\begin{array}{c}\rho_{\text {exp }} \\
\left(\mathrm{g} \cdot \mathrm{cm}^{-3}\right)\end{array}$ & $\begin{array}{c}\rho_{\text {theo }} \\
\left(\mathrm{g} \cdot \mathrm{cm}^{-3}\right)\end{array}$ & $\begin{array}{c}\rho_{\text {exp }} / \rho_{\text {theo }} \\
(\%)\end{array}$ \\
\hline ZK60 & $110.2 \pm 2.3$ & 1.807 & 1.812 & 99.7 \\
ZK60/10HA & $106.4 \pm 4.4$ & 1.841 & 1.893 & 97.3 \\
\hline
\end{tabular}

\subsection{Electrochemical test}

Figure 4 presents the electrochemical polarization curves of ZK60 and ZK60/10HA. As listed in Table 3, the corrosion current density of ZK60 is $824.5 \mu \mathrm{A} \cdot \mathrm{cm}^{-2}$, which is 3.2 times higher than ZK60/10HA. Since the corrosion current density is related to the corrosion rate, a decrease in the corrosion current density indicates increased corrosion resistance. Therefore, according to the results of the electrochemical tests, ZK60/10HA has a better corrosion resistance in the SBF solution than ZK60. A similar result with $\mathrm{Mg} / \mathrm{HA}$ and $\mathrm{Mg}-3 \mathrm{Zn} /$ HA composites was observed in Refs. [6, 25]. The improvement in the corrosion resistance of ZK60/10HA can be attributed to the grain refinement and apatiteinducibility of HA.

\subsection{Wear test under dry conditions}

The surface roughness $\left(R_{a}\right)$ of the ZK60 and ZK60/10HA

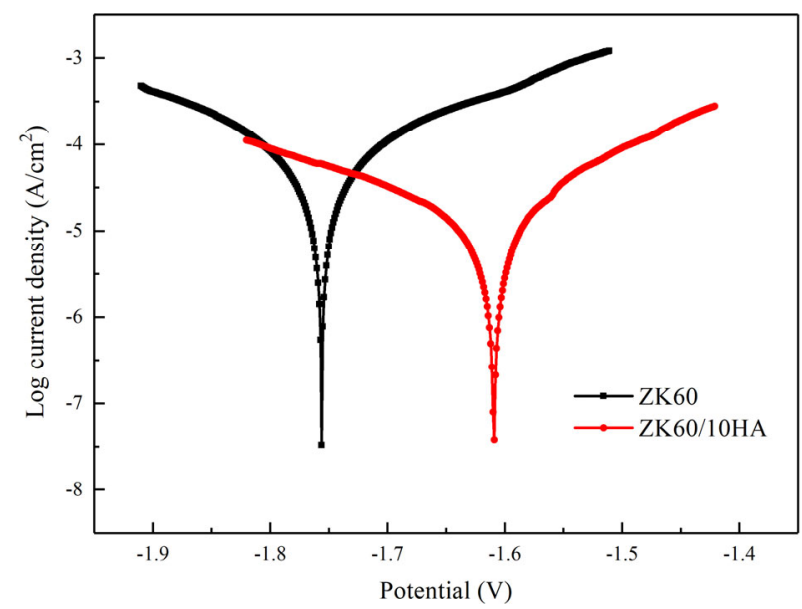

Fig. 4 Electrochemical polarization curves of ZK60 and ZK60/10HA.

Table 3 Electrochemical data of ZK60 and ZK60/10HA.

\begin{tabular}{ccc}
\hline Sample & $E_{\text {corr }}(\mathrm{V})$ & $I_{\text {corr }}\left(\mu \mathrm{A} \cdot \mathrm{cm}^{-2}\right)$ \\
\hline ZK60 & -1.76 & 824.5 \\
ZK60/10HA & -1.64 & 281.4 \\
\hline
\end{tabular}


samples prior to wear tests was 0.386 and $0.408 \mu \mathrm{m}$, respectively. The coefficients of friction (CoF) of ZK60 and $\mathrm{ZK} 60 / 10 \mathrm{HA}$ as a function of time under dry conditions are displayed in Fig. 5, which was recorded during the sliding process. The CoF of ZK60 and ZK60/10HA remained constant during the sliding test, at values of approximately 0.38 and 0.32 , respectively.

The $\omega$ of ZK60 and ZK60/10HA, measured under the dry conditions as a function of sliding velocity, is shown in Fig. 6. ZK60/10HA exhibited a higher $\omega$ compared to ZK60 under all the sliding velocities tested. In addition, the $\omega$ of both samples was not sensitive to sliding velocity.

Figures 7(a) and 7(b) present the scanning electron microscopy (SEM) images of the worn surfaces of ZK60 and ZK60/10HA, respectively. From the images, it is obvious that the predominant wear mechanism

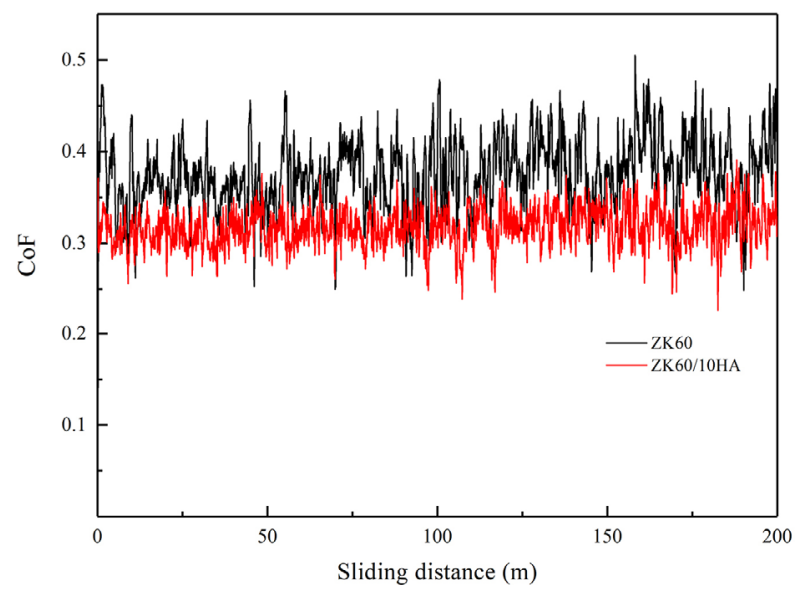

Fig. $5 \mathrm{CoF}$ of ZK60 and ZK60/10HA as a function of time under dry conditions at a sliding velocity of $3,770 \mathrm{~mm} / \mathrm{min}$.

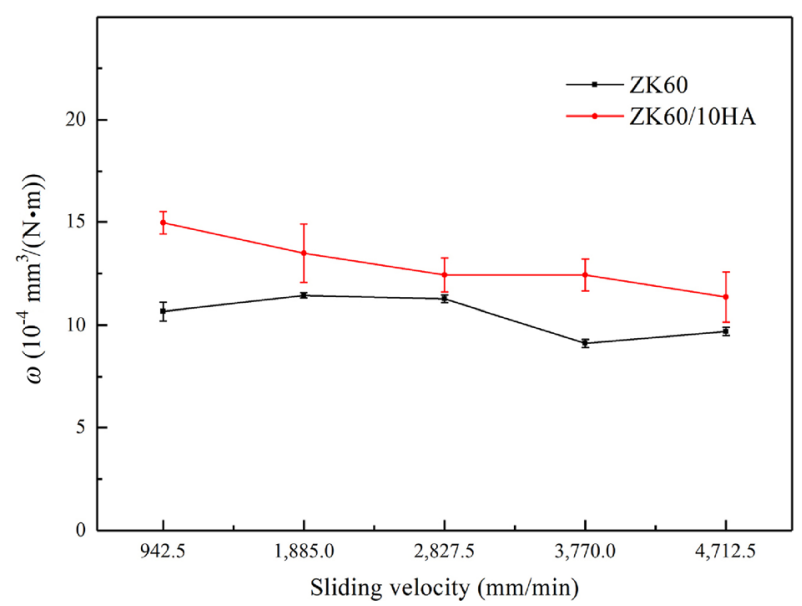

Fig. $6 \omega$ of ZK60 and ZK60/10HA as a function of sliding velocity under dry conditions.
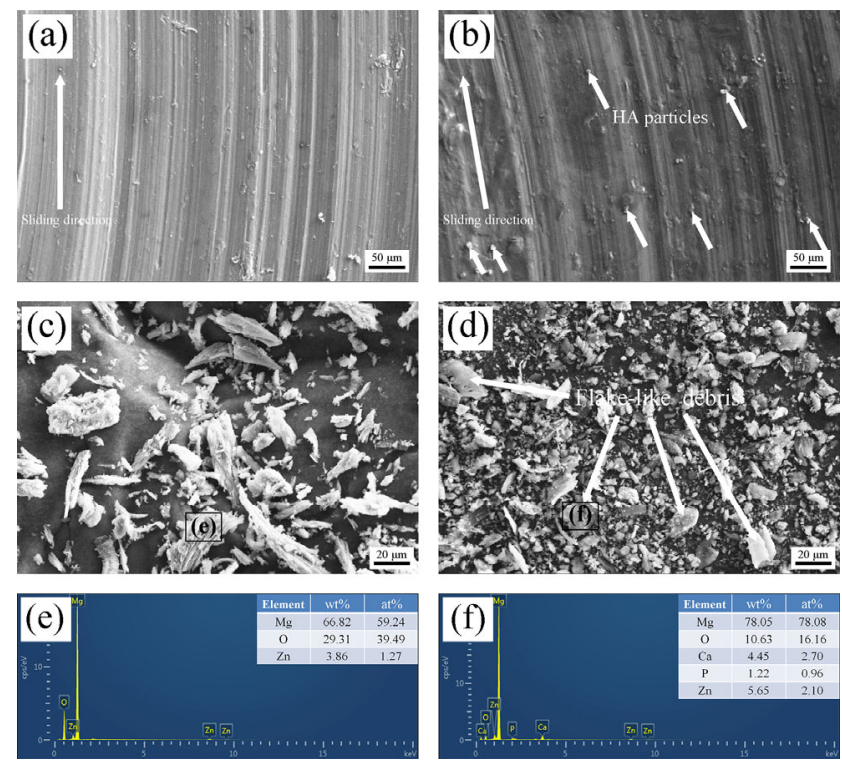

Fig. 7 SEM secondary electron images (SEI) of the worn surface and wear debris of $(\mathrm{a}, \mathrm{c}) \mathrm{ZK} 60$ and $(\mathrm{b}, \mathrm{d}) \mathrm{ZK} 60 / 10 \mathrm{HA}$ under dry conditions at a sliding velocity of $3,770 \mathrm{~mm} / \mathrm{min}$; EDS spectrum of the debris from (e) ZK60 and (f) ZK60/10HA.

for both samples was abrasive. Typical fine grooves parallel to the sliding direction can be found in both samples, which resulted from the abrasive effect of the steel counterface. In addition, as shown in Fig. 7(b), some of HA particles detached from the matrix and fractured during the sliding wear test. The detached and fractured HA particles were trapped and embedded in the counterface, which eventually led to three-body abrasion.

Figures 7(c) and 7(d) show the SEM images of the wear debris, and Figs. 7(e) and 7(f) present the EDS results of the wear debris for ZK60 and ZK60/10HA, respectively. EDS analysis was performed on the rectangular regions shown in Figs. 7(c) and 7(d). The EDS results indicate that the main components of the wear debris from ZK60 and ZK60/10HA were Mg and $\mathrm{O}$, which indicate that oxidation occurred during the wear tests. The wear debris from ZK60/10HA was much finer than that of ZK60, which can be attributed to the HA particles that led to three-body abrasion. The wear debris collected from ZK60/10HA had a diameter of $1-20 \mu \mathrm{m}$, which is finer than the agglomerated HA particles shown in Fig. 3(d) (about $50-100 \mu \mathrm{m})$. The results indicate that the HA agglomerate was broken down and dispersed during the wear test. Moreover, some flake-like debris can be 
found in Fig. 7(d), indicating that delamination wear also occurred.

\subsection{Wear test in SBF solution}

The CoFs of ZK60 and ZK60/10HA as a function of time in the SBF solution are shown in Fig. 8. The CoFs of ZK60 and ZK60/10HA are 0.20 and 0.28 , respectively. Compared with the tests under dry conditions, there was a decreased in the fluctuations and value of the CoF for both samples in the SBF solution, which indicates that the SBF solution has a lubricating effect during the sliding process.

The $\omega$ of ZK60 and ZK60/10HA measured in the SBF solution as a function of sliding velocity is presented in Fig. 9. With increasing sliding velocity, the $\omega$ of both ZK60 and ZK60/10HA decreased gradually. For all the sliding velocities tested, the corrosion-wear

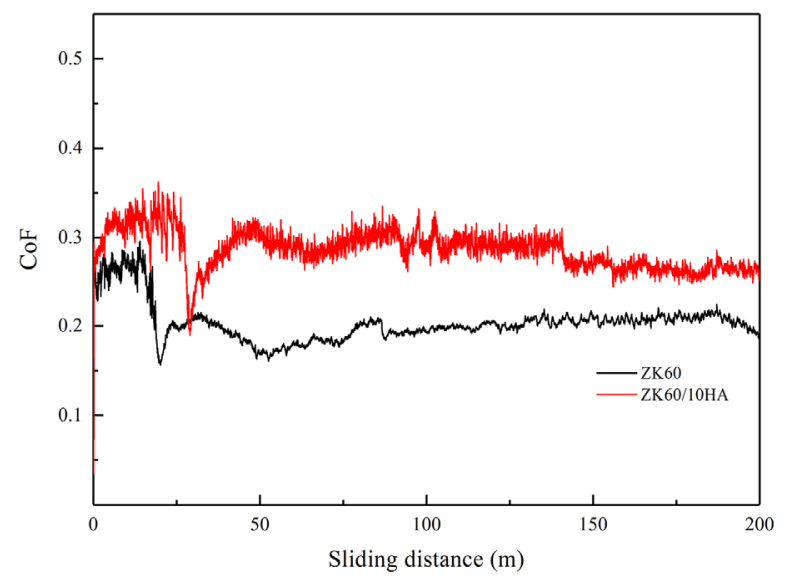

Fig. $8 \mathrm{CoF}$ of ZK60 and ZK60/10HA as a function of time in the $\mathrm{SBF}$ solution at a sliding velocity of $3,770 \mathrm{~mm} / \mathrm{min}$.

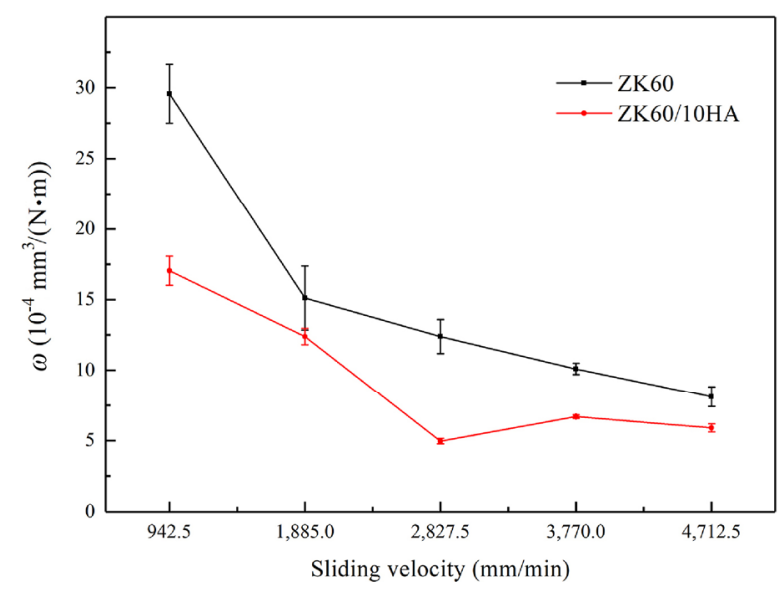

Fig. $9 \omega$ of ZK60 and ZK60/10HA as a function of sliding velocity in the SBF solution. resistance of ZK60/10HA was superior to ZK60. At a sliding velocity of $942.5 \mathrm{~mm} / \mathrm{min}$, the $\omega$ of ZK60 and ZK60/10HA was 29.58 and $17.05 \times 10^{-4} \mathrm{~mm}^{3} /(\mathrm{N} \cdot \mathrm{m})$, respectively.

Figure 10 (a) shows an SEM image of the ZK60 worn surface in the SBF solution. Due to the effects of corrosion, no obvious wear tracks can be found on the surface. Similar to immersion samples of magnesium alloys, many cracks are observed on the surface. These cracks are due to the larger volume of $\mathrm{Mg}(\mathrm{OH})_{2}$ than $\mathrm{MgO}$ as the cracks formed when $\mathrm{Mg}(\mathrm{OH})_{2}$ was converted to $\mathrm{MgO}$ during the sample drying process. According to the elemental mapping results, the worn tracks were covered by a layer of $\mathrm{MgO}$. Moreover, a small amount of $\mathrm{Ca}$ and $\mathrm{P}$ were also found on the surface, which can be attributed to the deposition of $\mathrm{Ca}^{2+}$ and $\mathrm{HPO}^{4-}$ ions from the SBF solution that occurred during the sliding of the steel counterface.

Figure 11(a) presents an SEM image of the ZK60/ 10HA worn surface in the SBF solution. Consistent with the $\omega$, a flatter wear track was observed on the ZK60/10HA surface, which can be attributed to the presence of the HA particles. The results of the
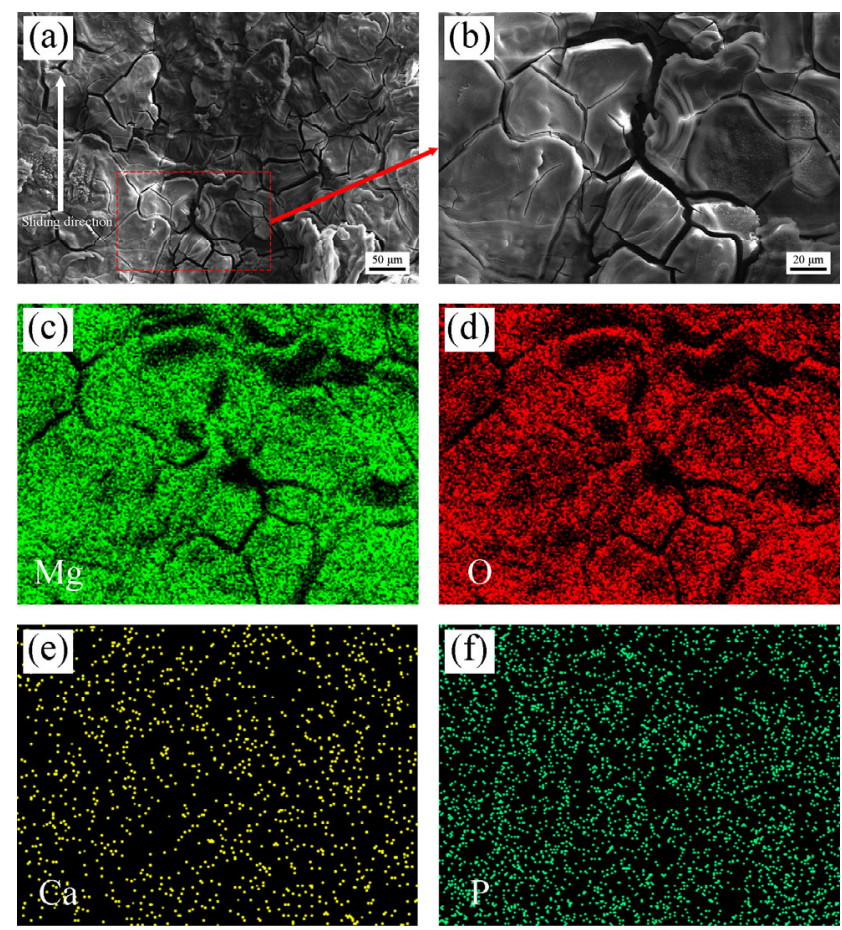

Fig. 10 SEM SEI of the worn surface of $(a, b)$ ZK60 in the SBF solution before removing the corrosion products, and (c-f) elemental mapping of the ZK60 worn surface (after using a sliding velocity of $3,770 \mathrm{~mm} / \mathrm{min}$ in the wear tests). 

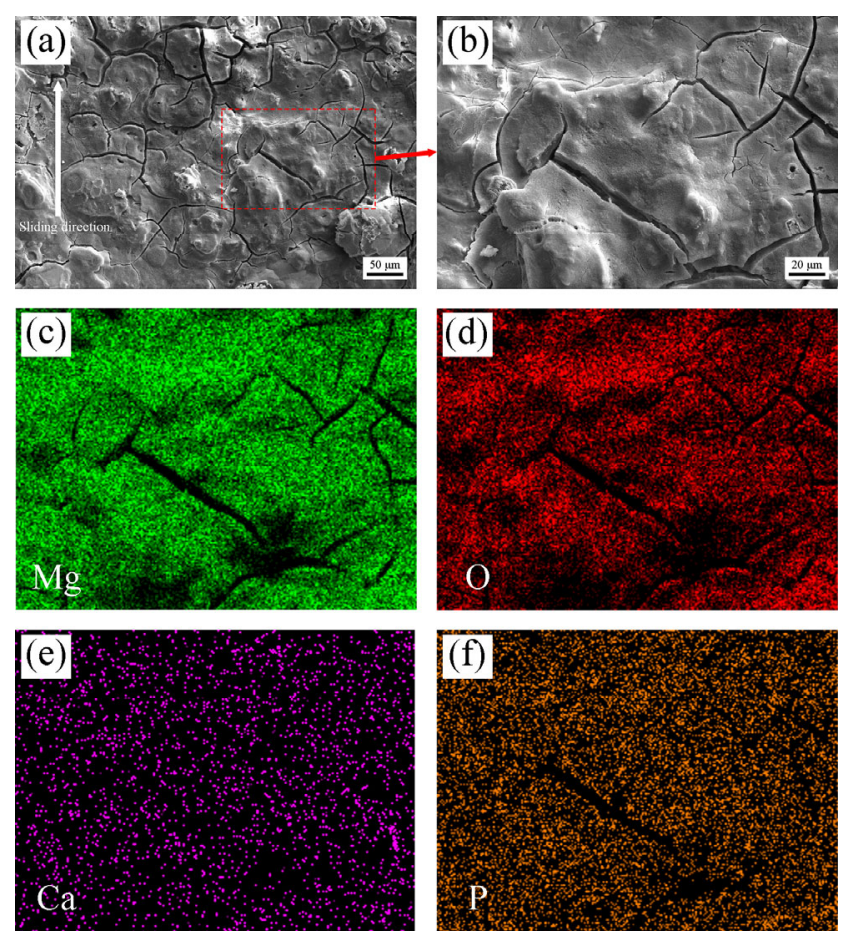

Fig. 11 SEM SEI of the worn surface of $(a, b)$ ZK60/10HA in the SBF solution before removing the corrosion products, and (c-f) elemental mapping of the ZK60/10HA worn surface (after using a sliding velocity of $3,770 \mathrm{~mm} / \mathrm{min}$ in the wear tests).

elemental mapping indicate that the main constituents of the worn surface were $\mathrm{Mg}, \mathrm{O}, \mathrm{Ca}$, and $\mathrm{P}$. More $\mathrm{Ca}$ and $\mathrm{P}$ atoms were observed in ZK60/10HA than in ZK60. These $\mathrm{Ca}$ and $\mathrm{P}$ atoms can be attributed to the presence of $\mathrm{HA}$, which induced the deposition of $\mathrm{Ca}^{2+}$ and $\mathrm{HPO}^{4-}$ from the SBF solution to form the bone-like apatite [6].

After the sliding wear tests, the wear debris was filtered from the testing fluid and dried in air. Figures 12(a) and 12(b) present the SEM images of the wear debris from ZK60 and ZK60/10HA, respectively. For both samples, small debris, caused by abrasive wear, was formed. Flake-like debris was only observed in $\mathrm{ZK} 60 / 10 \mathrm{HA}$, indicating that delamination wear also took place. Compared to the debris from ZK60/10HA under dry conditions (Fig. 7(d)), it is clear that delamination and three-body abrasion were reduced in the SBF solution. EDS analysis was performed on the rectangular region shown in Figs. 12(a) and 12(b). The EDS results show that the main elements present in the wear debris from $\mathrm{ZK} 60$ were $\mathrm{Mg}$ and $\mathrm{O}$, which were from $\mathrm{Mg}(\mathrm{OH})_{2}$. Moreover, a small number of other elements in the SBF solution remained in the wear debris after the drying process. For ZK60/10HA, in addition to $\mathrm{Mg}$ and $\mathrm{O}, \mathrm{Ca}$ and $\mathrm{P}$ were also rich in the debris, as shown in Figs. 12(d) and 12(e). As discussed above, the $\mathrm{Ca}$ and $\mathrm{P}$ can be attributed to the presence of $\mathrm{HA}$, which can induce the deposition of $\mathrm{Ca}^{2+}$ and $\mathrm{HPO}^{4-}$ ions from the SBF solution.

To observe the morphology of the matrix, ultrasonic cleaning in a chromic acid solution $\left(200 \mathrm{~g} / \mathrm{L} \mathrm{CrO}_{3}+\right.$ $10 \mathrm{~g} / \mathrm{L} \mathrm{AgNO}_{3}$ ) was used to remove corrosion products on the surface of the wear specimens. The SEM images of the worn surfaces of ZK60 and ZK60/10HA after removing the corrosion products are shown in Fig. 13. The main surface morphology feature found on ZK60 was the formation of many deep pits, which were caused by the pitting corrosion of $\mathrm{Cl}^{-}$.

As shown in Fig. 13(b), many holes were found on ZK60/10HA, which are different from those on the surface of ZK60. According to the size and morphology of these holes, it can be inferred that they were caused
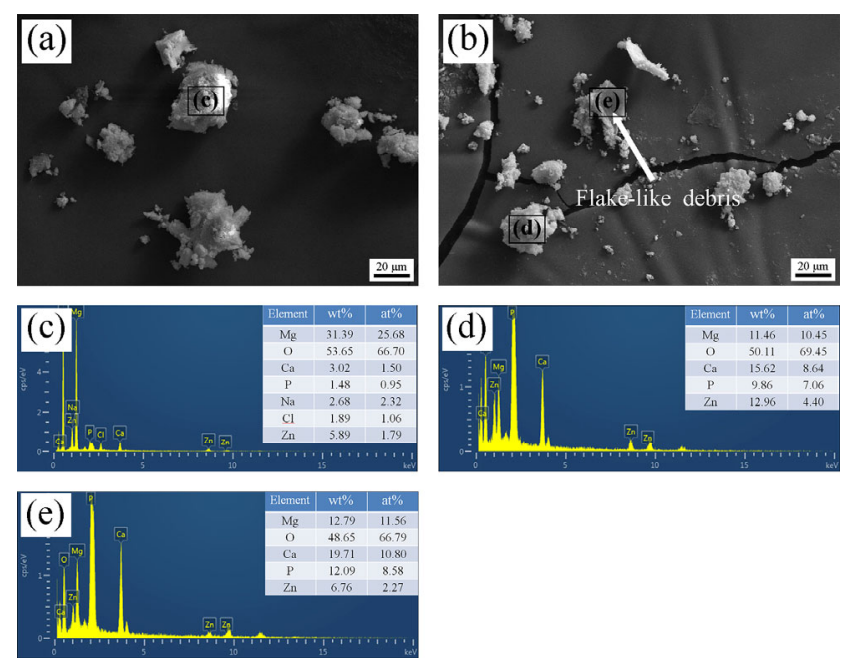

Fig. 12 SEM SEI of the wear debris from (a) ZK60 and (b) ZK60/10HA in the SBF solution (sliding velocity of 3,770 $\mathrm{mm} / \mathrm{min}$ ), and EDS spectrum obtained from the debris of (c) ZK60 and (d, e) ZK60/10HA.
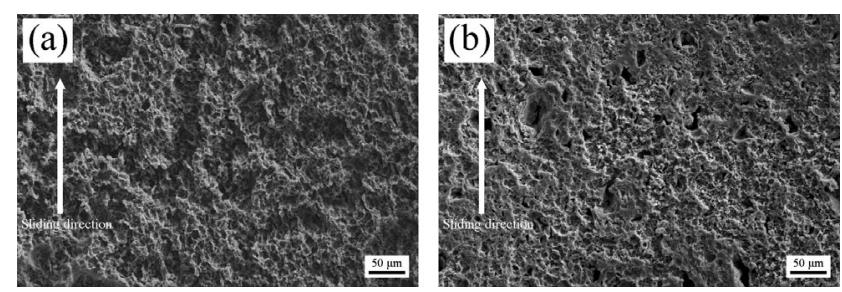

Fig. 13 SEM SEI of (a) ZK60 and (b) ZK60/10HA worn surfaces after removing the corrosion products (sliding velocity of $3,770 \mathrm{~mm} / \mathrm{min}$ ). 
by the peeling of the HA particles during the corrosion products removal. The peeling of the HA particles is due to the ultrasonic vibration and the severe chemical reaction between $\mathrm{Mg}(\mathrm{OH})_{2}$ and the chromic acid. The areas around the hole are flat and smooth, which confirms that the HA particles can effectively carry the load under sliding and that it resists the wear effect of the steel counterface.

Figure 14 presents the SEM images of the transverse cross-section of ZK60 and ZK60/10HA worn surfaces before removing the corrosion products. The surface of ZK60/10HA was much flatter than ZK60 due to the presence of the HA particles. This shows that the corrosion-wear resistance of ZK60/10HA is greater than ZK60. Moreover, cracks and voids can be found in ZK60/10HA, as shown in Fig. 14(b).

\section{Discussion}

\subsection{Wear test under dry conditions}

According to the results shown in Fig. 5, the lower CoF of ZK60/10HA compared to ZK60 can be attributed to the presence of the reinforcement particles [26]. Since the hardness of HA (480 HV) is much higher than that of ZK60 (110.2 HV), the magnesium matrix around the HA particles was more quickly worn out at the initial stage of the sliding test [27]. Next, the HA particles begin to carry the load as they are in maximum contact with the counterpart steel ball. At this point, the contact area of the friction pair will be reduced, so that the $\mathrm{CoF}$ of ZK60/10HA will be reduced to some extent [26]. Meanwhile, according to the worn surface and wear debris shown in Fig. 7, there is a third body effect due to the presence of HA particles, which will lead to an increase in the CoF. To summarize,
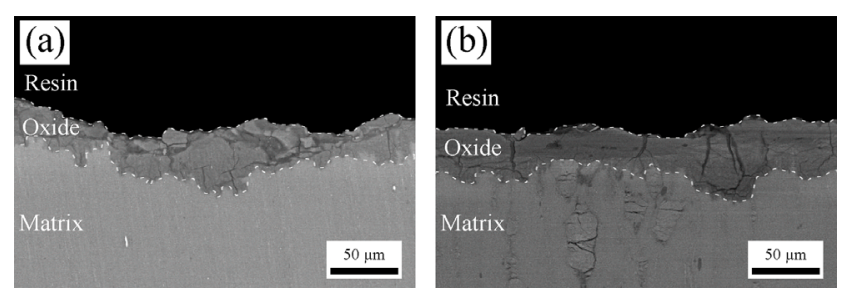

Fig. 14 SEM back scattered electron (BSE) images of the transverse cross-section of (a) ZK60 and (b) ZK60/10HA worn surfaces before removing the corrosion products (sliding velocity of $3,770 \mathrm{~mm} / \mathrm{min}$ ). the CoF was affected by two competing factors: (1) the load carrying effect of the HA particles which lead to a lower $\mathrm{CoF}$; (2) the third body effect that then increased the CoF. According to the CoF shown in Fig. 5, the first factor appears to be dominant in this study.

Previous studies have shown that by incorporating hard reinforcement particles, the $\omega$ of a metal matrix composite can be effectively controlled due to the load carrying effect of the reinforcement particles [28]. If the bonding strength between the matrix and reinforcement particles is strong enough to resist wear, then the load will be mainly supported by the reinforcement particles. In this case, the wear resistance of the composite will be effectively enhanced. However, when the interface bonding between the matrix and reinforcement particles is too weak to resist wear, then the reinforcement particles will fall out of the matrix during the sliding process. In this case, the load carrying effect of the reinforcement particles during the sliding wear test cannot be fully utilized. Moreover, the detached reinforcement particles will act as extra abrasives in the sliding test, and thus lead to more severe three-body abrasion.

Compared to ZK60, the higher $\omega$ of ZK60/10HA under dry conditions can be attributed to the weak interface bonding between the alloy matrix and the HA particles. It is difficult to keep the reinforcing particles on the surface intact during the wear test. In addition, due to the higher hardness of the HA particles compared to ZK60, shedding of the HA particles from the matrix will result in three-body abrasion, which is conducive to abrasive wear.

The hardness and porosity can also explain the wear behavior under dry conditions. As shown in Table 2, ZK60/10HA (106.4 HV) exhibited a lower hardness than ZK60 (110.2 HV). According to Archard's law, a lower hardness corresponds to a higher $\omega$. Moreover, under dry conditions, the porosity of the composite also has a detrimental effect on the wear resistance. During the sliding wear test, the presence of voids promotes the initiation and propagation of cracks, and thereby leading to more severe abrasive wear [29].

In addition, the agglomerated HA particles deteriorated the plasticity of the composite and 
promoted the initiation and propagation of cracks in the subsurface, and at this point, delamination wear occurred. The combination of all these reasons explain why the wear resistance of the alloy was greater than the composite under dry conditions.

\subsection{Wear test in SBF solution}

As shown in Fig. 8, the CoF of the composite was higher than that of the alloy in the SBF solution. This can be attributed to the presence of the HA particles, which have a higher hardness than ZK60. Unlike in the wear test under dry conditions, it is more difficult to reduce the roughness due to the lubricating effect of the SBF solution. At this point, the CoF value of ZK60/10HA was higher than ZK60.

As shown in Fig. 9, the $\omega$ of ZK60 and ZK60/10HA decreased gradually with increasing sliding velocity. As the sliding speed increases, the rotation period becomes shorter, and thus, resulted in less corrosion [3]. This was the main factor causing the $\omega$ reduction.

For ZK60, there was a greater $\omega$ in the SBF solution than under the dry conditions when the sliding velocity was lower than $4,712.5 \mathrm{~mm} / \mathrm{min}$. This indicates that the SBF solution plays a predominant role as a corrosion solution during the sliding wear test. ZK60 reacted with the SBF solution to form porous $\mathrm{Mg}(\mathrm{OH})_{2}$ during the sliding motion, and when the $\mathrm{Cl}^{-}$ion concentration in the aqueous solution was more than $30 \mathrm{mmol} \cdot \mathrm{L}^{-1}$, the $\mathrm{Mg}(\mathrm{OH})_{2}$ was then readily transformed to soluble $\mathrm{MgCl}_{2}$ [30]. The highly soluble $\mathrm{MgCl}_{2}$ can easily be worn out in the subsequent wear process. Thus, the $\omega$ was increased due to the synergistic effect of corrosion and wear.

For ZK60/10HA, there was a lower $\omega$ in the SBF solution than under the dry conditions for all the sliding velocities tested, and thus indicating that the SBF solution acted as a lubricant. The frictional force was reduced, and the wear debris was carried away by the SBF solution. This allowed the hard HA particles to effectively carry the load during the sliding wear tests. Meanwhile, there was less delamination wear and three-body abrasion in ZK60/10HA, as can be seen in Figs. 7(d) and 12(b). Moreover, the porosity also had a substantial effect on the corrosion-wear behavior. According to Ref. [31], the voids in composites act as lubricant reservoirs or lubricating channels under wet conditions, and thereby improving the wear resistance. As shown in Fig. 14(b), the cracks and voids formed in the subsurface acted as excellent lubricant reservoirs, which led to the low $\omega$. In addition, there was less corrosion observed as the corrosion resistance ZK60/10HA is higher than that of ZK60. Previous studies have demonstrated that $\mathrm{HA}$ can induce the deposition of $\mathrm{Ca}^{2+}$ and $\mathrm{HPO}^{4-}$ ions from the SBF solution, leading to the formation of a bonelike apatite [6]. More importantly, the apatite formed on the worn surface is uniform and compacted due to the normal force acting on it during the sliding wear test. This uniform and compacted apatite layer on the worn surface can effectively hinder corrosion caused by $\mathrm{Cl}^{-}$ions, and thereby increasing the corrosion-wear resistance of the composite. The hardness had limited influence on its corrosion-wear behavior; hence, it cannot be used to explain the reduced $\omega$ of ZK60/10HA $\omega$ in the SBF solution [22]. All the factors mentioned above led to the improvement in the corrosion-wear resistance with the incorporation of $\mathrm{HA}$ in the SBF solution. Therefore, the HA particles can be considered as an effective corrosion-wear inhibitor in biocompatible magnesium matrix composites.

\section{Conclusions}

In this study, ZK60 alloy and ZK60/10HA composites were fabricated by powder metallurgy. The effects of the HA particles on the corrosion-wear behavior were evaluated. The main conclusions that can be drawn are as follows:

1) Grain refinement was observed with the addition of HA to ZK60. ZK60/10HA consists of two phases: $\alpha-\mathrm{Mg}$ and HA. According to the electrochemical measurements, ZK60/10HA exhibited a better corrosion resistance than ZK60.

2) Under dry conditions, the $\omega$ of ZK60 and ZK60/ $10 \mathrm{HA}$ is basically unaffected by the sliding velocity. In the SBF solution, the $\omega$ of the two materials decreased with increasing sliding velocity.

3) Based on the results of the sliding wear tests, improved corrosion-wear resistance was observed in ZK60/10HA compared to ZK60 for all the sliding 
velocities tested. This indicates that the HA particles act as an effective corrosion-wear inhibitor in biocompatible magnesium matrix composites. Compared to ZK60, the corrosion-wear resistance of ZK60/10HA improved by $42 \%$ at a sliding velocity of $942.5 \mathrm{~mm} / \mathrm{min}$.

4) For ZK60, the main wear mechanism under dry conditions is abrasion, and in the SBF solution, they are abrasion and corrosion. For ZK60/10HA, the main wear mechanisms under dry conditions are abrasion and delamination, and in the SBF solution they are mainly abrasion and corrosion, accompanied by slight delamination.

\section{Acknowledgements}

This study was supported by National Natural Science Foundation of China (Nos. 51574118 and 51674118).

Open Access This article is licensed under a Creative Commons Attribution 4.0 International License, which permits use, sharing, adaptation, distribution and reproduction in any medium or format, as long as you give appropriate credit to the original author(s) and the source, provide a link to the Creative Commons licence, and indicate if changes were made.

The images or other third party material in this article are included in the article's Creative Commons licence, unless indicated otherwise in a credit line to the material. If material is not included in the article's Creative Commons licence and your intended use is not permitted by statutory regulation or exceeds the permitted use, you will need to obtain permission directly from the copyright holder.

To view a copy of this licence, visit http://creativecommons.org/licenses/by/4.0/.

\section{References}

[1] Staiger M P, Pietak A M, Huadmai J, Dias G. Magnesium and its alloys as orthopedic biomaterials: A review. Biomaterials 27(9): 1728-1734 (2006)

[2] Nayak S, Bhushan B, Jayaganthan R, Gopinath P, Agarwal $\mathrm{R}$ D, Lahiri D. Strengthening of $\mathrm{Mg}$ based alloy through grain refinement for orthopaedic application. J Mech Behav Biomed Mater 59: 57-70 (2016)

[3] Yang X Y, Hutchinson C R. Corrosion-wear of $\beta$-Ti alloy
TMZF (Ti-12Mo-6Zr-2Fe) in simulated body fluid. Acta Biomater 42: 429-439 (2016)

[4] Song G L. Control of biodegradation of biocompatable magnesium alloys. Corros Sci 49(4): 1696-1701 (2007)

[5] Mróz W, Bombalska A, Burdyńska S, Jedyński M, Prokopiuk A, Budner B, Ślósarczyk A, Zima A, Menaszek E, ŚcisłowskaCzarnecka A, et al. Structural studies of magnesium doped hydroxyapatite coatings after osteoblast culture. J Mol Struct 977(1-3): 145-152 (2010)

[6] Shuai C J, Zhou Y Z, Yang Y W, Feng P, Liu L, He C X, Zhao M C, Yang S, Gao C D, Wu P. Biodegradation resistance and bioactivity of hydroxyapatite enhanced $\mathrm{Mg}$-Zn composites via selective laser melting. Materials 10(3): 307 (2017)

[7] Gu X N, Zhou W R, Zheng Y F, Dong L M, Xi Y L, Chai D L. Microstructure, mechanical property, bio-corrosion and cytotoxicity evaluations of $\mathrm{Mg} / \mathrm{HA}$ composites. Mater $\mathrm{Sci}$ Eng C 30(6): 827-832 (2010)

[8] Jaiswal S, Kumar R M, Gupta P, Kumaraswamy M, Roy P, Lahiri D. Mechanical, corrosion and biocompatibility behaviour of Mg-3Zn-HA biodegradable composites for orthopaedic fixture accessories. J Mech Behav Biomed Mater 78: 442-454 (2018).

[9] Sunil B R, Ganapathy C, Sampath Kumar T S, Chakkingal U. Processing and mechanical behavior of lamellar structured degradable magnesium-hydroxyapatite implants. $J$ Mech Behav Biomed Mater 40: 178-189 (2014)

[10] del Campo R, Savoini B, Muñoz A, Monge M A, Garcés G, Mechanical properties and corrosion behavior of $\mathrm{Mg}-\mathrm{HAP}$ composites. J Mech Behav Biomed Mater 39: 238-246 (2014)

[11] Zhang X B, Dai J W, Zhang J, Bai Y Q. Quantitative evaluation of the interaction between wear and corrosion on Mg-3Gd-1Zn alloy in simulated body fluid. J Mater Eng Perform 28: 355-362 (2019)

[12] Liu D B, Wu B, Wang X, Chen M F. Corrosion and wear behavior of an $\mathrm{Mg}-2 \mathrm{Zn}-0.2 \mathrm{Mn}$ alloy in simulated body fluid. Rare Metals 34(8): 553-559 (2015)

[13] Watson S W, Friedersdorf F J, Madsen B W, Cramer S D. Methods of measuring wear-corrosion synergism. Wear 181-183: 476-484 (1995)

[14] Batchelor A W, Stachowiak G W. Predicting synergism between corrosion and abrasive wear. Wear 123(3): 281-291 (1988)

[15] Gupta U C, Gupta S C. Sources and deficiency diseases of mineral nutrients in human health and nutrition: A review. Pedosphere 24(1): 13-38 (2014)

[16] Cai S H, Lei T, Li N F, Feng F F. Effects of Zn on microstructure, mechanical properties and corrosion behavior of Mg-Zn alloys. Mater Sci Eng C 32(8): 2570-2577 (2012) 
[17] Chen Y J, Xu Z G, Smith C, Sankar J. Recent advances on the development of magnesium alloys for biodegradable implants. Acta Biomater 10(11): 4561-4573 (2014)

[18] Edwards J T, Brunski J B, Higuchi H W. Mechanical and morphologic investigation of the tensile strength of a bonehydroxyapatite interface. J Biomed Mater Res 36(4): 454-468 (1997)

[19] Haghshenas M. Mechanical characteristics of biodegradable magnesium matrix composites: A review. J Magnes Alloys 5(2): 189-201 (2017)

[20] Buciumeanu M, Araujo A, Carvalho O, Miranda G, Souza J C M, Silva F S, Henriques B. Study of the tribocorrosion behaviour of Ti6Al4V-HA biocomposites. Tribol Int 107: 77-84 (2017)

[21] Doni Z, Alves A C, Toptan F, Rocha L A, Buciumeanu M, Palaghian L, Silva F S. Tribocorrosion behaviour of hot pressed CoCrMo-HAP biocomposites. Tribol Int 91: 221-227 (2015)

[22] Kokubo T, Takadama H. How useful is SBF in predicting in vivo bone bioactivity? Biomaterials 27(15): 2907-2915 (2006)

[23] Kumar A, Biswas K, Basu B. Fretting wear behaviour of hydroxyapatite-titanium composites in simulated body fluid, supplemented with $5 \mathrm{~g} \cdot \mathrm{l}^{-1}$ bovine serum albumin. $J$ Phys $D$ Appl Phys 46(40): 404004 (2013)

[24] Bovand D, Yousefpour M, Rasouli S, Bagherifard S, Bovand N, Tamayol A. Characterization of Ti-HA composite fabricated by mechanical alloying. Mater Design 65: 447-453 (2015)

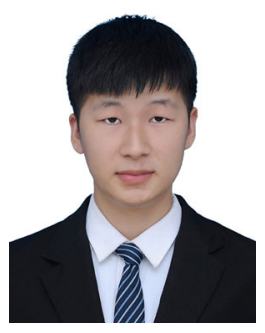

Jinlong SU. He received his B.S. degree in material forming and control engineering in 2017 from University of South China, China.

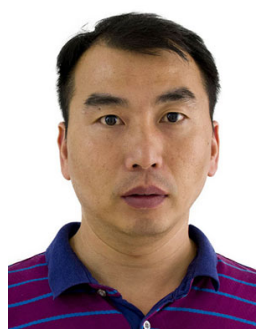

Jie TENG. He received his Ph.D. degree in materials processing engineering from Hunan University in 2006, China. Then, he joined the College of Materials Science and
[25] Xiong G Y, Nie Y J, Ji D H, Li J, Li C Z, Li W, Zhu Y, Luo H L, Wan Y Z. Characterization of biomedical hydroxyapatite/magnesium composites prepared by powder metallurgy assisted with microwave sintering. Curr Appl Phys 16(8): 830-836 (2016)

[26] Kumar G N, Narayanasamy R, Natarajan S, Babu S P K, Sivaprasad K, Sivasankaran S. Dry sliding wear behaviour of AA $6351-\mathrm{ZrB}_{2}$ in situ composite at room temperature. Mater Des 31(3): 1526-1532 (2010)

[27] Niespodziana K, Jurczyk K, Jakubowicz J, Jurczyk M. Fabrication and properties of titanium-hydroxyapatite nanocomposites. Mater Chem Phys 123(1): 160-165 (2010)

[28] Roy M, Venkataraman B, Bhanuprasad V V, Mahajan Y R, Sundararajan G. The effect of participate reinforcement on the sliding wear behavior of aluminum matrix composites. Metallurg Trans A 23(10): 2833-2847 (1992)

[29] Lim S C, Brunton J H. The unlubricated wear of sintered iron. Wear 113(3): 371-382 (1986)

[30] Persaud-Sharma D, McGoron A. Biodegradable magnesium alloys: A review of material development and applications. J Biomim Biomater Tissue Eng 12: 25-39 (2012)

[31] Yugeswaran S, Yoganand C P, Kobayashi A, Paraskevopoulos K M, Subramanian B. Mechanical properties, electrochemical corrosion and in-vitro bioactivity of yttria stabilized zirconia reinforced hydroxyapatite coatings prepared by gas tunnel type plasma spraying. J Mech Behav Biomed Mater 9: 22-33 (2012)

Then, he was a master student in Hunan University, China. His research interests include tribology and corrosion of metal matrix composites and biomedical materials.

Engineering, Hunan University, China. His current position is a professor and his research areas cover the tribology and corrosion of metal matrix composites and biomedical materials. 


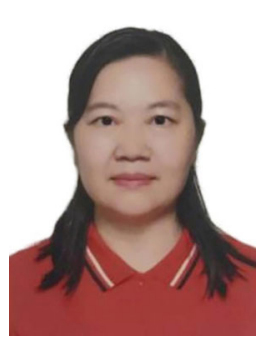

Zili XU. She received her Ph.D. degree in surgery from Central South University in 2009, China. Then, she joined the Hunan
Provincial People's Hospital Orthopedics, China. Her current position is a professor and her research areas cover the bone tumors, peripheral nerve lesions injury, and biomedical materials.

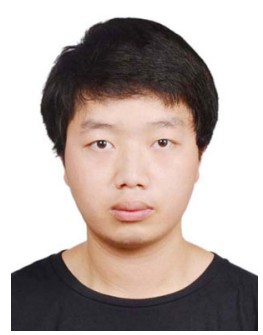

Yuan LI. He received his B.S. Hunan Normal Universiy, China. His research degree in medical science in 2016 interests include bone tumors, peripheral nerve injury, from Hunan Normal University, and biomedical materials.

China. He is a master student in 